\title{
Air pollution and airway resistance at age 8 years - the PIAMA birth cohort study
}

Isabelle Finke ${ }^{1}$, Johan C. de Jongste ${ }^{2}$, Henriette A. Smit ${ }^{3}$, Alet H. Wijga ${ }^{4}$, Gerard H. Koppelmann ${ }^{5,6}$, Judith Vonk ${ }^{6,7}$, Bert Brunekreef ${ }^{1,3}$ and Ulrike Gehring ${ }^{1 *}$ (i)

\begin{abstract}
Background: Air pollution has been found to adversely affect children's lung function. Forced expiratory volume in $1 \mathrm{~s}$ and forced vital capacity from spirometry have been studied most frequently, but measurements of airway resistance may provide additional information. We assessed associations of long-term air pollution exposure with airway resistance.
\end{abstract}

Methods: We measured airway resistance at age 8 with the interrupter resistance technique $\left(R_{\text {int }}\right)$ in participants of the Dutch PIAMA birth cohort study. We linked $R_{\text {int }}$ with estimated annual average air pollution concentrations [nitrogen oxides $\left(\mathrm{NO}_{2}, \mathrm{NO}_{x}\right), \mathrm{PM}_{2.5}$ absorbance ("soot"), and particulate matter $<2.5 \mu \mathrm{m}\left(\mathrm{PM}_{2.5}\right),<10 \mu \mathrm{m}\left(\mathrm{PM}_{10}\right)$ and 2.5-10 $\left.\mu \mathrm{m}\left(\mathrm{PM}_{\text {coarse }}\right)\right]$ at the birth address and current home address $(n=983)$. Associations between air pollution exposure and interrupter resistance $\left(R_{\text {int }}\right)$ were assessed using multiple linear regression adjusting for potential confounders.

Results: We found that higher levels of $\mathrm{NO}_{2}$ at the current address were associated with higher $\mathrm{R}_{\text {int }}$ [adj. mean difference (95\% confidence interval) per interquartile range increase in $\mathrm{NO}_{2}: 0.018(0.001,0.035) \mathrm{kPa} \cdot \mathrm{s} \cdot \mathrm{L}^{-1} \mathrm{]}$. Similar trends were observed for the other pollutants, except, $\mathrm{PM}_{10}$. No association was found between $\mathrm{R}_{\mathrm{int}}$ and exposure at the birth address.

Conclusions: Our results support the hypothesis that air pollution exposure is associated with a lower lung function in schoolchildren.

Keywords: Air pollution, Children, Interrupter resistance, Particulate matter, Nitrogen dioxide

\section{Background}

Lung development starts in utero and tracks throughout life $[1,2]$. Therefore, maximum attained lung function in early adulthood likely will be suboptimal in those with a low lung function in early childhood and the threshold for respiratory symptoms and disability like chronic obstructive pulmonary disease will be reached earlier $[3,4]$.

There is growing evidence for adverse effects of long-term exposure to ambient air pollution on the lung function of children from cross-sectional and longitudinal studies [5-7]. Spirometry is considered the gold standard for measuring lung function and forced expiratory volume in $1 \mathrm{~s}\left(\mathrm{FEV}_{1}\right)$, is often used as a measure of

\footnotetext{
* Correspondence: U.Gehring@uu.nl

${ }^{1}$ Institute for Risk Assessment Sciences, Utrecht University, P.O. Box 80178,

3508TD Utrecht, The Netherlands

Full list of author information is available at the end of the article
}

airway obstruction in epidemiological studies [5]. However, reproducible spirometry is often not possible in children. Interrupter resistance $\left(R_{\text {int }}\right)$ requires less skill and cooperation, and is feasible in young children $[8,9]$. Moreover, since air flow limitations are partly caused by increased airway resistance, direct measurements of airway resistance may provide additional information [10].

Only four studies so far investigated associations between long-term air pollution exposure and airway resistance and only one of them has repeated measures of airway resistance to study changes in associations with age. Findings of these studies are inconsistent. Higher ambient air pollution exposure early in life was associated with higher peripheral airway resistance from impulse oscillometry (R5-R20) at age 16 in a Swedish birth cohort [11], and with higher $R_{\text {int }}$ at age 4 in our PIAMA birth cohort [12]. Living within $50 \mathrm{~m}$ of a busy

(c) The Author(s). 2018 Open Access This article is distributed under the terms of the Creative Commons Attribution 4.0 International License (http://creativecommons.org/licenses/by/4.0/), which permits unrestricted use, distribution, and 
road was associated with a higher airway resistance $\left(R_{a w}\right)$ in a cross-sectional study of children aged 5-7 years from Eastern and Western Germany [13]. In contrast, no association was found between life-time exposure to air pollution and repeated measures of specific airway resistance $\left(S_{\text {raw }}\right)$ at ages $3,5,8$, and 11 years in a birth cohort from Manchester [14].

With the present study, we add to the currently limited evidence regarding the association between long-term air pollution exposure and airway resistance with age. We analyzed associations of air pollution exposure with $R_{\text {int }}$ at age 8 years and changes in $R_{\text {int }}$ between 4 and 8 years within the prospective PIAMA (Prevention and Incidence of Asthma and Mite Allergy) birth cohort study for which we previously reported positive associations between $R_{\text {int }}$ at the age of 4 years and annual average exposure to $\mathrm{NO}_{2}, \mathrm{PM}_{2.5}$ and "soot" at the birth address [12].

\section{Methods}

\section{Study design and study population}

Details on the PIAMA birth cohort study have been published elsewhere $[15,16]$. In brief, pregnant women were recruited from the general population in 19961997 through antenatal clinics in the north, west and center of the Netherlands. Non-allergic pregnant women were invited to participate in a "natural history" study arm. Pregnant women identified as allergic through a screening questionnaire were allocated primarily to an intervention arm with a random subset allocated to the natural history arm. The intervention involved the use of mite-impermeable mattress and pillow covers.

The study started with 3963 newborns. Parents completed questionnaires on demographic factors, risk factors for asthma and respiratory symptoms at birth, at the child's ages 3 months and 1 year and then annually until the age of 8 years [16]. At the age of 8 , all children of allergic mothers and a random sample of children of non-allergic mothers (total $n=1680$ ) were invited for an extensive medical examination and 1235 participated. As part of the medical examination, interrupter resistance $\left(R_{\text {int }}\right)$ was successfully measured in 1003 children. We excluded children who had used asthma medication during the $12 \mathrm{~h}$ prior to the $\mathrm{R}_{\text {int }}$ testing $(n=11)$ and children with missing data on use of asthma medication $(n=9)$. The final study population for this study consisted of 983 children with successful $R_{\text {int }}$ measurements and information on air pollution exposure at the birth address $(n=975)$ and/or current home address $(n=965)$.

The Institutional Review Boards of the participating institutes approved the study protocol, and written informed consent was obtained from the parents or legal guardians of all participants.

\section{$\mathrm{R}_{\text {int }}$ measurements}

$R_{\text {int }}$ at the age of 8 years was our primary outcome. Between October 11, 2004 and December 10, 2005 we measured $R_{\text {int }}$ (MicroRint, Micro Medical Ltd., Rochester, Kent, UK) by trained personnel while sitting upright, breathing quietly and wearing a nose clip with support of cheeks and chin $[8,17]$. All measurements were performed with a filter (Micro Medical Ltd) in place. Shutter closure was programmed at maximal expiratory tidal flow. $R_{\text {int }}$ was calculated as the ratio of mouth pressure before and immediately after occlusion of the airway to airflow $\left(\mathrm{kPa} \cdot \mathrm{s} \cdot \mathrm{L}^{-1}\right)$. Tracings were inspected immediately after the measurement in the presence of the child. Rejection criteria were: tachypnea, usage of the vocal cords, extreme neck flexion or extension, and leakage of the mouthpiece. $R_{\text {int }}$ was calculated as the median of at least five acceptable measurements out of ten for each child.

For a subset of the participants with $R_{\text {int }}$ measurements at age $8, R_{\text {int }}$ measurements from an earlier medical examination at age 4 years, using the same methodology, were available together with information on annual average air pollution exposure at the home address at the time of the 4-year $\mathrm{R}_{\text {int }}$ measurement $(n=521)$. For these participants we calculated the change in $R_{\text {int }}$ between 4 and 8 years of age as a secondary outcome.

\section{Air pollution exposure assessment}

We estimated annual average air pollution concentrations at the participants' birth addresses and current addresses at the time of the $R_{\text {int }}$ measurements with spatial land-use regression models that have been developed within the EU-funded ESCAPE (European Study of Cohorts for Air Pollution Effects) project $[18,19]$. These land-use regression models are different from the land-use regression models from the TRAPCA (TrafficRelated Air Pollution and Childhood Asthma) project [20] that have been used in the earlier analyses at age 4 [12]. The new ESCAPE models have a better performance than the TRAPCA models and enable us to investigate associations with nitrogen oxides $\left(\mathrm{NO}_{\mathrm{x}}\right)$ and particulate matter with diameters of less than less than $10 \mu \mathrm{m}$ $\left(\mathrm{PM}_{10}\right)$ and $2.5-10 \mu \mathrm{m}\left(\mathrm{PM}_{\text {coarse }}\right)$ in addition to nitrogen dioxide $\left(\mathrm{NO}_{2}\right)$, particulate matter with diameters of less than $2.5 \mu \mathrm{m}\left(\mathrm{PM}_{2.5}\right)$, and $\mathrm{PM}_{2.5}$ absorbance ("soot", determined as the reflectance of $\mathrm{PM}_{2.5}$ filters). In brief, for the ESCAPE land-use regression models air pollution monitoring campaigns were performed between October 2008 and February 2010 in the study area. Three 2-week measurements of $\mathrm{NO}_{2}$ and $\mathrm{NO}_{\mathrm{x}}$ were performed at 80 sites within 1 year. Simultaneous measurements of $\mathrm{PM}_{2.5}$, $\mathrm{PM}_{10}, \mathrm{PM}_{\text {coarse }}$, and $\mathrm{PM}_{2.5}$ absorbance were performed at 40 of these sites. Results from the three measurements were averaged to estimate the annual average [21]. We 
evaluated predictor variables of nearby traffic, population and household density, and land use derived from Geographic Information Systems to explain spatial variation in annual average concentrations. The land-use regression models were then used to estimate annual average air pollution concentrations at participants' home addresses, for which the same Geographic Information Systems predictor variables were obtained, without adjustment for long-term changes in air pollution levels. Overall model performance was evaluated by leave-one-out cross-validation: Each site was sequentially left out from the model while the included variables were left unchanged. A brief description of the models including their performance is provided in Additional file 1: Table S1. The estimated annual average air pollution concentrations from the land-use regression models were our primary estimates of exposure. Since air pollution measurements were performed in 2008-2010, but cohort participants were born in 1996-1997, in addition, we extrapolated predicted concentrations for the birth addresses (for which the time difference with the ESCAPE measurements was largest) back in time to account for long-term changes in air pollution levels using the ratio between the years prior and after birth and the ESCAPE monitoring year, based on data from routine background monitoring network sites in the study areas (for details see http://www.escapeproject.eu/manuals/). We used data from two years to avoid back-extrapolation being influenced too much by specific weather circumstances in a specific year. This may become important when a cohort was recruited in multiple years.

\section{Covariates}

Covariates were selected a priori based on previous analyses at age 4 and published literature. Information on sex, parental education (low: primary school, lower vocational or lower secondary education; medium: intermediate vocational education or intermediate/higher secondary education; high: higher vocational education and university), parental allergy (yes/no), maternal smoking during pregnancy (yes/no), smoking in the child's home (yes/no), mold or dampness in the living room and/or child's bedroom (yes/no), any pets in the child's home (yes/no), use of gas for cooking (yes/no), presence of an unvented gas water heater in the child's home (yes/ no), presence of older siblings (yes/no), and Dutch nationality (yes/no) was obtained from the parent-completed questionnaires. Information on season, participant's age, height, and weight was collected during the medical examination. Data on ambient temperature and relative humidity on the day of the $R_{\text {int }}$ measurements was retrieved from the Royal Netherlands Meteorological Institute (KNMI, http://www.knmi.nl/nederland-nu/klimatologie/gemeten-reeksen). Daily average concentrations of $\mathrm{NO}_{2}, \mathrm{PM}_{10}$, and black smoke ("soot") on the day of the medical examination were obtained from the Dutch National Air Quality Monitoring Network (NAQMN, https://www.lml.rivm. nl/gevalideerd/index.php/).

\section{Data analysis}

The association of $R_{\text {int }}$ at age 8 years with annual average air pollution concentrations at the birth address and current home address at the time of the 8-year $R_{\text {int }}$ measurements were analyzed by multiple linear regression with and without adjustment for the potential confounding variables described above. We adjusted for the same potential confounders as in previous analyses at age 4 (i.e. sex, parental education, parental allergy, maternal smoking during pregnancy, smoking in the child's home, mold or dampness, pets, use of gas for cooking, presence of a unvented gas water heater, older siblings, Dutch nationality) and air pollution levels on the day of the $R_{\text {int }}$ measurements. Covariates were selected from the questionnaire that coincided best with the exposure period. We performed available case analyses, which results in slightly different numbers of observations for the different models.

In our secondary analysis, associations of changes in $R_{\text {int }}$ from age 4 to 8 years with annual average air pollution concentrations during the period between the two $R_{\text {int }}$ measurements, taking into account changes in residential address and occupancy at different addresses, were analyzed by multiple linear regression with and without adjustment for the same confounders $(n=519$ of the 521 participants had complete information on exposure during that period).

We performed a sensitivity analysis to explore to what extent associations with air pollution exposures at the birth address depended on the use of a purely spatial (ESCAPE non back-extrapolated) or temporal-spatial (ESCAPE back-extrapolated) model or the choice of the land-use regression models (ESCAPE models vs TRAPCA models that were used in analyses with $R_{\text {int }}$ at age 4). Moreover, we performed separate analyses for children with and without asthma at age 8 and for children who did and did not change address at any time between birth and the 8-year $\mathrm{R}_{\text {int }}$ measurement. Asthma was defined as a positive answer to at least two of the three following questions: (1) "Has a doctor ever diagnosed asthma in your child?", (2) "Has your child had wheezing or whistling in the chest in the last 12 months?", (3) "Has your child been prescribed asthma medication during the last 12 months?", a definitions that has been developed by a panel of experts within the MeDALL consortium [22].

Functional relationships of the associations between annual average air pollution concentrations and $R_{\text {int }}$ at 
age 8 were explored using smoothing splines. As exposure-response did not deviate significantly $(p<0.05)$ from linearity, except for $\mathrm{PM}_{2.5}$ (see Additional file 1: Figures S1 and S2), air pollution levels were entered as continuous variables without transformation in all models. Residual plots were used to check model assumptions. Associations were assessed in single-pollutant models and are presented as mean change in the dependent variable for an interquartile range increase in exposure to facilitate comparison of effect sizes between pollutants. Statistical significance was defined by a two-sided $\alpha$-level $\leq 5 \%$, marginal statistical significance by a two-sided $\alpha$-level $\leq 10 \%$.

All analyses were performed using SAS statistical software (version 9.4; SAS Institute Cary, NC, USA).

\section{Results}

Characteristics of the study population are presented in Table 1. About half of the participants were female and most had a Dutch nationality. By design, participants of the intervention study were overrepresented among participants of the 8-year medical examination and consequently the percentage of children with allergic parents was higher in the current study population than in the full cohort (75\% vs $51 \%)$. Other than that, differences between the current study population and the full cohort were small (see Additional file 1: Table S2). Mean (SD) $\mathrm{R}_{\text {int }}$ at age 8 was $0.66(0.16) \mathrm{kPa} \cdot \mathrm{s} \cdot \mathrm{L}^{-1}$ (Table 2), which is slightly higher than what would be expected based on published reference values for children being about $1.30 \mathrm{~m}$ tall [23]. $\mathrm{R}_{\text {int }}$ at age 8 years was on average (SD) $0.30(0.21) \mathrm{kPa} \cdot \mathrm{s} \cdot \mathrm{L}^{-1}$ lower than $\mathrm{R}_{\text {int }}$ at age 4 years.

The distributions of the estimated annual average air pollution concentrations at the participants' birth address, current home address at the time of the 8-year $R_{\text {int }}$ measurements, and for the period between the 4and 8-year $R_{\text {int }}$ measurements are shown in Table 3. Exposure contrasts were larger for $\mathrm{NO}_{2}, \mathrm{NO}_{\mathrm{x}}$ and $\mathrm{PM}_{2.5}$ absorbance than for $\mathrm{PM}_{2.5}, \mathrm{PM}_{10}$ and $\mathrm{PM}_{\text {coarse. Distribu- }}$ tions of daily average air pollution concentrations, temperature and relative humidity on the day of the $R_{\text {int }}$ measurements are presented in Table S3 in Additional file 1. Correlations between annual average concentrations of $\mathrm{NO}_{2}, \mathrm{NO}_{\mathrm{x}}$ and $\mathrm{PM}_{2.5}$ absorbance were high for both birth and current addresses $(r=0.90-0.92$, see Additional file 1: Table S4) and moderate to high for $\mathrm{PM}_{10}$ and $\mathrm{PM}_{\text {coarse }}$ Correlations between annual average concentrations at the birth address and current address for the same pollutant were high $(r=0.74-0.85)$. Correlations between annual average air pollution concentrations and daily average concentrations on the day of the $\mathrm{R}_{\text {int }}$ measurements were generally low $(r=0.02-0.42$, see Additional file 1: Table S5).
Table 1 Description of the study population

\begin{tabular}{|c|c|c|}
\hline Variable & $n / N$ & $(\%)$ \\
\hline Female sex & $504 / 983$ & (51) \\
\hline \multicolumn{3}{|l|}{ Parental education } \\
\hline Low & $110 / 981$ & (11) \\
\hline Medium & $343 / 981$ & (35) \\
\hline High & $528 / 981$ & (54) \\
\hline Parental allergy & 739/983 & (75) \\
\hline Maternal smoking during pregnancy & $147 / 974$ & (15) \\
\hline \multicolumn{3}{|l|}{ Smoking in the child's home } \\
\hline First year of life & 233/980 & $(24)$ \\
\hline Current $^{a}$ & 138/916 & (15) \\
\hline \multicolumn{3}{|c|}{ Mold/dampness in living room and/or child's bedroom } \\
\hline First year of life & 69/970 & (7) \\
\hline Current $^{\mathrm{a}}$ & $51 / 910$ & (6) \\
\hline \multicolumn{3}{|l|}{ Pets in the child's home } \\
\hline First year of life & $446 / 981$ & (45) \\
\hline Current $^{a}$ & $454 / 900$ & $(50)$ \\
\hline \multicolumn{3}{|l|}{ Use of gas for cooking } \\
\hline First year of life & $788 / 965$ & $(82)$ \\
\hline Current $^{\mathrm{a}}$ & $732 / 958$ & (76) \\
\hline \multicolumn{3}{|l|}{ Unvented gas water heater } \\
\hline First year of life & $44 / 931$ & (5) \\
\hline Current $^{\mathrm{a}}$ & $21 / 932$ & (2) \\
\hline Older siblings & $469 / 982$ & $(48)$ \\
\hline Dutch nationality & $913 / 964$ & (95) \\
\hline Asthma & $103 / 957$ & (11) \\
\hline Did not move house since birth & $505 / 973$ & (52) \\
\hline
\end{tabular}

${ }^{a}$ Age 8 years except for use of gas for cooking and unvented gas water heater, where no information was available from the 8-year questionnaire and data from the 5-year questionnaire were used

${ }^{b}$ Defined as 2 out of the 3 following criteria: asthma ever, wheeze in the past 12 months and prescription of asthma medication in the past 12 months

$R_{\text {int }}$ tended to be higher in children with higher estimated annual average concentrations of all pollutants except $\mathrm{PM}_{\text {coarse }}$ at the current address, but this was less consistent for exposures at the birth address (Table 4). Associations attenuated after adjustment for potential confounders, but remained marginally statistically significant for $\mathrm{NO}_{2}, \mathrm{NO}_{\mathrm{x}}$ and $\mathrm{PM}_{2.5}$ absorbance at the current address and $\mathrm{PM}_{2.5}$ at the birth address $(p<0.10)$.

Table 2 Description of $R_{\text {int }}$ measurements at age 8 years

\begin{tabular}{lll}
\hline Variable & $N$ & Mean (SD) \\
\hline Rint $\left[\mathrm{kPa} \cdot \mathrm{s} \cdot \mathrm{L}^{-1}\right]$ & 983 & $0.66(0.16)$ \\
Age $^{\mathrm{a}}[\mathrm{years}]$ & 983 & $8.1(0.3)$ \\
Height $^{\mathrm{a}}[\mathrm{cm}]$ & 983 & $132.8(5.7)$ \\
Weight $^{\mathrm{a}}[\mathrm{kg}]$ & 983 & $28.9(4.9)$ \\
\hline
\end{tabular}

${ }^{\mathrm{a}}$ At the time of $\mathrm{R}_{\text {int }}$ measurements 
Table 3 Distribution of annual average air pollution concentrations at the participants' birth address and current home address, and for the period between the 4- and 8-year $\mathrm{R}_{\text {int }}$ measurements

\begin{tabular}{|c|c|c|c|c|c|c|c|}
\hline & Min & P25 & Median & Mean & P75 & Max & $\mathrm{N}$ \\
\hline \multicolumn{8}{|l|}{ Annual average birth address } \\
\hline $\mathrm{NO}_{2}\left[\mu \mathrm{g} / \mathrm{m}^{3}\right]$ & 9.4 & 18.9 & 23.3 & 23.4 & 27.3 & 48.1 & 975 \\
\hline $\mathrm{NO}_{x}\left[\mu \mathrm{g} / \mathrm{m}^{3}\right]$ & 16.5 & 27.6 & 33.5 & 34.8 & 38.8 & 88.9 & 975 \\
\hline $\mathrm{PM}_{2.5}\left[\mu \mathrm{g} / \mathrm{m}^{3}\right]$ & 15.3 & 15.7 & 16.5 & 16.4 & 16.8 & 21.1 & 975 \\
\hline $\mathrm{PM}_{10}\left[\mu \mathrm{g} / \mathrm{m}^{3}\right]$ & 23.7 & 24.1 & 24.7 & 25.0 & 25.4 & 33.2 & 975 \\
\hline $\mathrm{PM}_{\text {coarse }}\left[\mu \mathrm{g} / \mathrm{m}^{3}\right]$ & 7.6 & 7.8 & 8.1 & 8.4 & 8.7 & 13.0 & 975 \\
\hline $\mathrm{PM}_{2.5}$ absorbance $\left[10^{-5} / \mathrm{m}\right]$ & 0.85 & 1.09 & 1.24 & 1.25 & 1.36 & 2.99 & 975 \\
\hline \multicolumn{8}{|c|}{ Annual average at current address ${ }^{a}$} \\
\hline $\mathrm{NO}_{2}\left[\mu \mathrm{g} / \mathrm{m}^{3}\right]$ & 9.4 & 18.2 & 22.7 & 22.6 & 26.6 & 52.1 & 965 \\
\hline $\mathrm{NO}_{x}\left[\mu \mathrm{g} / \mathrm{m}^{3}\right]$ & 16.5 & 26.1 & 32.1 & 33.3 & 37.3 & 100.1 & 965 \\
\hline $\mathrm{PM}_{2.5}\left[\mu \mathrm{g} / \mathrm{m}^{3}\right]$ & 14.9 & 15.6 & 16.5 & 16.4 & 16.8 & 19.3 & 965 \\
\hline $\mathrm{PM}_{10}\left[\mu \mathrm{g} / \mathrm{m}^{3}\right]$ & 23.7 & 24.0 & 24.6 & 24.8 & 25.2 & 29.8 & 965 \\
\hline $\mathrm{PM}_{\text {coarse }}\left[\mu \mathrm{g} / \mathrm{m}^{3}\right]$ & 7.6 & 7.8 & 8.0 & 8.3 & 8.5 & 11.2 & 965 \\
\hline $\mathrm{PM}_{2.5}$ absorbance $\left[10^{-5} / \mathrm{m}\right]$ & 0.85 & 1.06 & 1.22 & 1.22 & 1.33 & 2.13 & 965 \\
\hline \multicolumn{8}{|c|}{ Annual average for the period between the 4- and 8-year Rint measurement ${ }^{\mathrm{b}}$} \\
\hline $\mathrm{NO}_{2}\left[\mu \mathrm{g} / \mathrm{m}^{3}\right]$ & 9.4 & 19.1 & 23.0 & 22.9 & 26.7 & 40.4 & 519 \\
\hline $\mathrm{NO}_{x}\left[\mu \mathrm{g} / \mathrm{m}^{3}\right]$ & 16.5 & 27.0 & 32.8 & 33.9 & 37.8 & 82.7 & 519 \\
\hline $\mathrm{PM}_{2.5}\left[\mu \mathrm{g} / \mathrm{m}^{3}\right]$ & 15.3 & 15.8 & 16.5 & 16.4 & 16.8 & 20.4 & 519 \\
\hline $\mathrm{PM}_{10}\left[\mu \mathrm{g} / \mathrm{m}^{3}\right]$ & 23.7 & 24.1 & 24.6 & 24.9 & 25.2 & 33.3 & 519 \\
\hline $\mathrm{PM}_{\text {coarse }}\left[\mathrm{\mu g} / \mathrm{m}^{3}\right]$ & 7.6 & 7.8 & 8.1 & 8.3 & 8.5 & 11.9 & 519 \\
\hline $\mathrm{PM}_{2.5}$ absorbance $\left[10^{-5} / \mathrm{m}\right]$ & 0.85 & 1.09 & 1.24 & 1.23 & 1.33 & 1.99 & 519 \\
\hline
\end{tabular}

${ }^{a}$ At the time of the 8-year $R_{\text {int }}$ measurement

bonly for participants with successful $R_{\text {int }}$ measurements at both, ages 4 and 8 years

$R_{\text {int }}$ was on average between 0.011 and $0.018 \mathrm{kPa} \cdot \mathrm{s} \cdot \mathrm{L}^{-1}$ higher per interquartile range increase in exposure to these pollutants, which corresponds to $2-3 \%$ of the average $R_{\text {int }}$ of $0.66 \mathrm{kPa} \cdot \mathrm{s} \cdot \mathrm{L}^{-1}$.

Annual average air pollution exposure at during the period between the 4- and 8-year $R_{\text {int }}$ measurements was not associated with the change in $R_{\text {int }}$ between 4 and 8 years (see Additional file 1: Table S6).

Adjusted associations of $R_{\text {int }}$ at age 8 with air pollution concentrations were very similar for back-extrapolated ESCAPE models and the older TRAPCA land-use regression models for $\mathrm{NO}_{2}, \mathrm{PM}_{2.5}$, and $\mathrm{PM}_{2.5}$ absorbance that we used in previous analyses at age 4 instead of the more recent ESCAPE land-use regression models that were used in the main analysis, but twice as big as associations with non back-extrapolated exposure estimates from the ESCAPE models (Table 5). Associations with exposure at the current address were limited to non-asthmatics (Fig. 1), but the number of asthmatics was small and consequently confidence intervals were wide. The associations with annual average exposure at the current address did not differ between participants who did and who did not change address at any time between birth and the $R_{\text {int }}$ measurements (Fig. 2).

\section{Discussion}

Our results provide evidence that $R_{\text {int }}$ at age 8 years was higher in children with higher estimated annual average air pollution concentrations, in particular in children with higher concentrations of $\mathrm{NO}_{2}, \mathrm{NO}_{\mathrm{x}}$ and $\mathrm{PM}_{2.5}$ absorbance at the current address.

Our findings contribute to the growing body of evidence on the long-term effects of air pollution exposure on children's lung function. Most studies performed so far linked air pollution exposure to spirometry data [5] and $\mathrm{FEV}_{1}$ mostly reflects large airway patency [24]. The $R_{\text {int }}$ technique that has been used in the present study has been shown to detect changes in proximal and more distal airway function [25]. Given the low correlation $(r=-0.41)$ between $R_{\text {int }}$ and $F E V_{1}$ at age 8 in our study population, the present analyses may provide additional insight into the adverse effects of air pollution on the airways of children.

The present analysis extends earlier analyses of associations between air pollution exposure at the birth address and $R_{\text {int }}$ at age 4 years in the same cohort [12]. Height has been found to be the best predictor of $R_{\text {int }}$ in children and the observed decrease from age 4 to age 8 is in accordance with published reference eqs. 
Table 4 Associations ${ }^{a}$ between $R_{\text {int }}$ and estimated annual average air pollution concentrations at the birth address and current home address from single-pollutant models

\begin{tabular}{|c|c|c|c|c|c|c|}
\hline \multirow[t]{2}{*}{ Pollutant [increment] } & \multicolumn{3}{|c|}{ Model $1^{\mathrm{b}}$} & \multicolumn{3}{|c|}{ Model $2^{c}$} \\
\hline & $\beta$ & $(95 \% \mathrm{Cl})$ & $p$-value & $\beta$ & $(95 \% \mathrm{Cl})$ & $p$-value \\
\hline Birth address & & $N=975$ & & & $N=869$ & \\
\hline $\mathrm{NO}_{2}\left[8.4 \mu \mathrm{g} / \mathrm{m}^{3}\right]$ & 0.011 & $(-0.001,0.024)$ & 0.0831 & 0.005 & $(-0.010,0.021)$ & 0.4770 \\
\hline $\mathrm{NO}_{x}\left[11.2 \mu \mathrm{g} / \mathrm{m}^{3}\right]$ & 0.007 & $(-0.002,0.017)$ & 0.1195 & 0.002 & $(-0.008,0.013)$ & 0.6868 \\
\hline $\mathrm{PM}_{2.5}\left[1.1 \mu \mathrm{g} / \mathrm{m}^{3}\right]$ & 0.023 & $(0.007,0.039)$ & 0.0056 & 0.017 & $(-0.001,0.034)$ & 0.0611 \\
\hline $\mathrm{PM}_{10}\left[1.3 \mu \mathrm{g} / \mathrm{m}^{3}\right]$ & 0.006 & $(-0.004,0.016)$ & 0.2612 & 0.002 & $(-0.008,0.012)$ & 0.7013 \\
\hline $\mathrm{PM}_{\text {coarse }}\left[0.9 \mathrm{\mu g} / \mathrm{m}^{3}\right]$ & 0.003 & $(-0.008,0.013)$ & 0.6354 & 0.002 & $(-0.007,0.010)$ & 0.7391 \\
\hline $\mathrm{PM}_{2.5}$ abs. $\left[0.2710^{-5} / \mathrm{m}\right]$ & 0.013 & $(0.001,0.024)$ & 0.0274 & 0.008 & $(-0.004,0.021)$ & 0.1813 \\
\hline Current address $^{d}$ & & $N=965$ & & & $N=808$ & \\
\hline $\mathrm{NO}_{2}\left[8.4 \mu \mathrm{g} / \mathrm{m}^{3}\right]$ & 0.022 & $(0.008,0.035)$ & 0.0016 & 0.018 & $(0.001,0.035)$ & 0.0334 \\
\hline $\mathrm{NO}_{x}\left[11.2 \mu \mathrm{g} / \mathrm{m}^{3}\right]$ & 0.016 & $(0.006,0.026)$ & 0.0025 & 0.011 & $(-0.001,0.022)$ & 0.0781 \\
\hline $\mathrm{PM}_{2.5}\left[1.1 \mu \mathrm{g} / \mathrm{m}^{3}\right]$ & 0.024 & $(0.006,0.042)$ & 0.0106 & 0.017 & $(-0.004,0.039)$ & 0.1079 \\
\hline $\mathrm{PM}_{10}\left[1.1 \mu \mathrm{g} / \mathrm{m}^{3}\right]$ & 0.012 & $(0.001,0.023)$ & 0.0285 & 0.005 & $(-0.007,0.017)$ & 0.4275 \\
\hline $\mathrm{PM}_{\text {coarse }}\left[0.7 \mu \mathrm{g} / \mathrm{m}^{3}\right]$ & 0.006 & $(-0.004,0.016)$ & 0.2335 & 0.000 & $(-0.011,0.011)$ & 0.9974 \\
\hline $\mathrm{PM}_{2.5}$ abs. $\left[0.2710^{-5} / \mathrm{m}\right]$ & 0.020 & $(0.007,0.032)$ & 0.0017 & 0.014 & $(0.000,0.029)$ & 0.0496 \\
\hline
\end{tabular}

${ }^{a}$ Associations are presented as mean difference in $\mathrm{R}_{\text {int }}$ per interquartile range increase in air pollution exposure $(\beta)$ with $95 \%$ confidence intervals $(\mathrm{Cl})$

${ }^{\mathrm{b}}$ Adjusted for sex and age

'Adjusted for sex, age, height, weight, parental education, parental allergies, maternal smoking during pregnancy, smoking in the child's home, mold/dampness in living room and/or child's bedroom, pets in the child's home, use of gas for cooking, unvented gas water heater, older siblings, Dutch nationality, season; average air pollution concentration $\left(\mathrm{NO}_{2}\right.$ in models with long-term $\mathrm{NO}_{2}$ and $\mathrm{NO}_{\mathrm{x}} ; \mathrm{PM}_{10}$ in models with long-term $\mathrm{PM}_{2.5}, \mathrm{PM}_{10}$, and $\mathrm{PM}_{\text {coarse; }}$ black smoke in models with long-term $\mathrm{PM}_{2.5}$ absorbance), ambient temperature and relative humidity on the day of the $\mathrm{R}_{\text {int }}$ test

${ }^{\mathrm{d}}$ At the time of the Rint measurements

[23]. The observed $2-3 \%$ higher $R_{\text {int }}$ at age 8 years per interquartile range increase in air pollution levels is consistent with the association estimates at age 4 years (i.e. $0.025-0.031 \mathrm{kPa} \cdot \mathrm{s} \cdot \mathrm{L}^{-1}$ per interquartile range increase in exposure, which corresponds to $3 \%$ of the mean $\mathrm{R}_{\mathrm{int}}$ of $\left.0.96 \mathrm{kPa} \cdot \mathrm{s} \cdot \mathrm{L}^{-1}\right)$. Together with our finding that there was no association between air pollution exposure and change in $R_{\text {int }}$ between ages 4 and 8 years this suggests that the difference in $R_{\text {int }}$ between participants with high and low levels of air pollution exposure does not further increase with age, but remains rather constant between ages 4 and 8 years. Few other studies assessed the association between air pollution and airway resistance. Our findings confirm the findings of a Swedish birth cohort study that found that higher levels of $\mathrm{NO}_{\mathrm{x}}$ and $\mathrm{PM}_{10}$ early in life were associated with higher peripheral airway resistance (R5-R20) at age 16 [11]. In a cross-sectional study of more than 2500 children aged 5-7 years from Eastern and Western Germany living

Table 5 Adjusted associations ${ }^{a}$ between $\mathrm{R}_{\text {int }}$ and estimated annual average concentrations at the birth address from single-pollutant models - ESCAPE non back-extrapolated vs ESCAPE back-extrapolated vs TRAPCA land-use regression models

\begin{tabular}{|c|c|c|c|c|c|c|c|c|c|}
\hline \multirow[t]{2}{*}{ Pollutant } & \multicolumn{3}{|c|}{ ESCAPE model - non back-extrapolated } & \multicolumn{3}{|c|}{ ESCAPE model -back-extrapolated } & \multicolumn{3}{|c|}{ TRAPCA model } \\
\hline & $\beta$ & $(95 \% \mathrm{Cl})$ & $p$-value & $\beta$ & $(95 \% \mathrm{Cl})$ & $p$-value & $\beta$ & $(95 \% \mathrm{Cl})$ & $p$-value \\
\hline $\mathrm{NO}_{2}$ & 0.005 & $(-0.010,0.021)$ & 0.4770 & 0.012 & $(-0.001,0.026)$ & 0.0768 & 0.011 & $(-0.003,0.024)$ & 0.1228 \\
\hline $\mathrm{NO}_{x}$ & 0.002 & $(-0.008,0.013)$ & 0.6868 & 0.009 & $(-0.001,0.019)$ & 0.0935 & $--\mathrm{b}^{\mathrm{b}}$ & & \\
\hline $\mathrm{PM}_{2.5}$ & 0.017 & $(-0.001,0.034)$ & 0.0611 & 0.026 & $(0.009,0.043)$ & 0.0022 & 0.012 & $(-0.005,0.029)$ & 0.1543 \\
\hline $\mathrm{PM}_{10}$ & 0.002 & $(-0.008,0.012)$ & 0.7013 & 0.017 & $(0.001,0.033)$ & 0.0340 & $--\mathrm{b}^{\mathrm{b}}$ & & \\
\hline $\mathrm{PM}_{\text {coarse }}$ & 0.002 & $(-0.007,0.010)$ & 0.7391 & 0.010 & $(-0.002,0.023)$ & 0.1144 & $--^{-}$ & & \\
\hline $\mathrm{PM}_{2.5}$ abs. & 0.008 & $(-0.004,0.021)$ & 0.1813 & 0.016 & $(0.004,0.029)$ & 0.0113 & $0.012^{b}$ & $(-0.002,0.026)$ & 0.1055 \\
\hline
\end{tabular}

${ }^{a}$ Associations are presented as mean difference in $\mathrm{R}_{\text {int }}$ per interquartile range increase in air pollution exposure ( $\beta$ ) with $95 \%$ confidence intervals (Cl). Adjusted for sex, age, height, weight, parental education, parental allergies, maternal smoking during pregnancy, smoking in the child's home, mold/dampness in living room and/or child's bedroom, pets in the child's home, use of gas for cooking, unvented gas water heater, older siblings, Dutch nationality, season; average air pollution concentration $\left(\mathrm{NO}_{2}\right.$ in models with long-term $\mathrm{NO}_{2}$ and $\mathrm{NO}_{x} ; \mathrm{PM}_{10}$ in models with long-term $\mathrm{PM}_{2.5}, \mathrm{PM}_{10}$, and $\mathrm{PM}_{\text {coarsei }}$ black smoke in models with long-term $\mathrm{PM}_{2.5}$ absorbance), ambient temperature and relative humidity on the day of the $\mathrm{R}_{\text {int }}$ test 


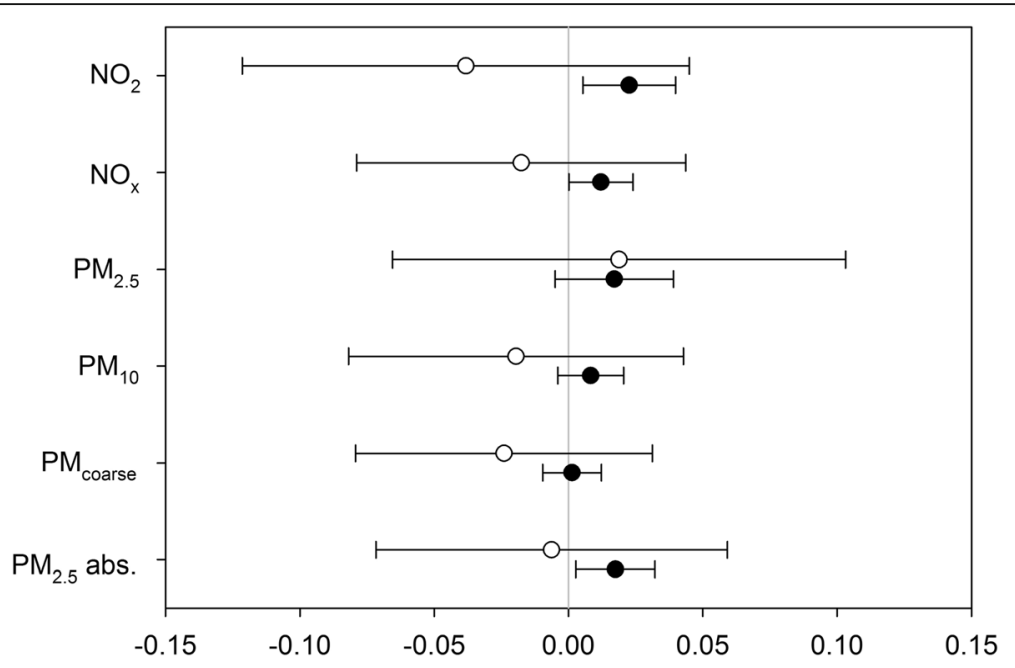

Adj. mean difference ( $95 \%$ confidence interval)

- non-asthma $\bigcirc$ asthma

Fig. 1 Associations between $R_{\text {int }}$ and estimated annual average concentrations at the current home address for children with and without asthma at age 8 years. Associations are presented as mean difference in $R_{\text {int }}$ per interquartile range increase in air pollution exposure ( $\beta$ ) with 95\% confidence intervals (Cl). Adjusted for sex, age, height, weight, parental education, parental allergies, maternal smoking during pregnancy, smoking in the child's home, mold/dampness in living room and/or child's bedroom, pets in the child's home, use of gas for cooking, unvented gas water heater, older siblings, Dutch nationality, season; average air pollution concentration $\left(\mathrm{NO}_{2}\right.$ in models with long-term $\mathrm{NO}_{2}$ and $\mathrm{NO}_{\mathbf{x}}$ PM $\mathrm{PM}_{10}$ in models with long-term $\mathrm{PM}_{2.5}, \mathrm{PM}_{10}$, and $\mathrm{PM}_{\text {coarsei }}$ black smoke in models with long-term $\mathrm{PM}_{2.5}$ absorbance), ambient temperature and relative humidity on the day of the $R_{\text {int }}$ test

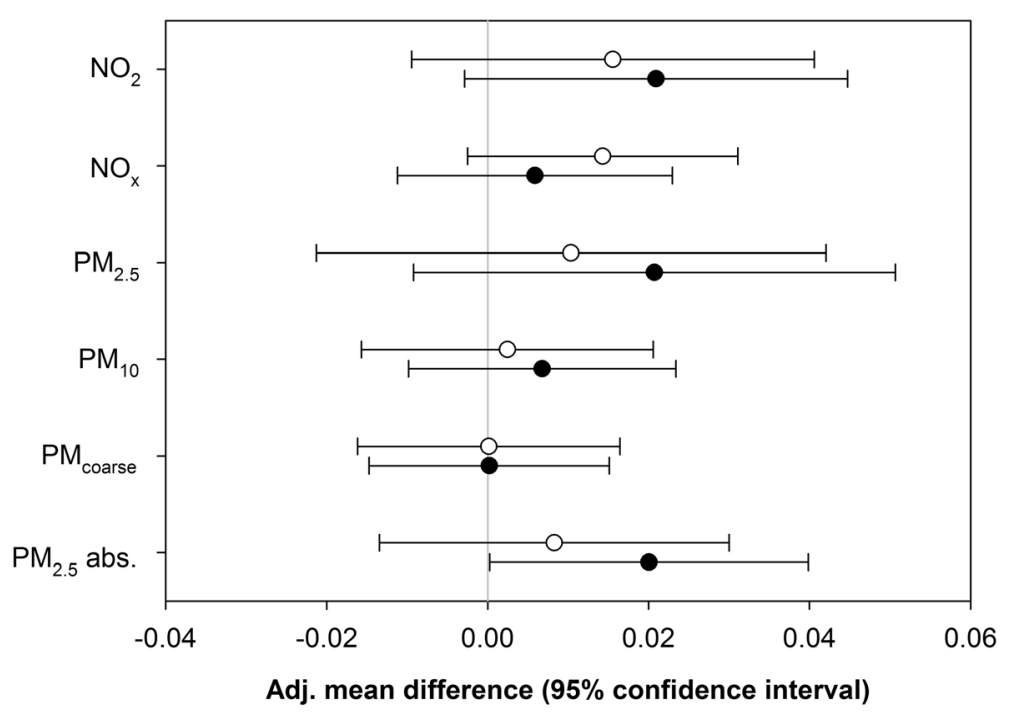

Fig. 2 Associations between $R_{\text {int }}$ and estimated annual average concentrations at the current home address for children who did and who did not change address at any time between birth and the $R_{\text {int }}$ measurements. Associations are presented as mean difference in $R_{\text {int }}$ per interquartile range increase in air pollution exposure ( $\beta$ ) with 95\% confidence intervals (Cl). Adjusted for sex, age, height, weight, parental education, parental allergies, maternal smoking during pregnancy, smoking in the child's home, mold/dampness in living room and/or child's bedroom, pets in the child's home, use of gas for cooking, unvented gas water heater, older siblings, Dutch nationality, season; average air pollution concentration $\left(\mathrm{NO}_{2}\right.$ in models with long-term $\mathrm{NO}_{2}$ and $\mathrm{NO}_{x i} \mathrm{PM}_{10}$ in models with long-term $\mathrm{PM}_{2.5}, \mathrm{PM}_{10}$, and $\mathrm{PM}_{\text {coarse; }}$ black smoke in models with long-term $\mathrm{PM}_{2.5}$ absorbance), ambient temperature and relative humidity on the day of the $\mathrm{R}_{\text {int }}$ test 
within $50 \mathrm{~m}$ of a busy road, but not annual average concentration of total suspended particles, was associated with higher $R_{a w}$ [13]. In contrast, no associations were found between life-time exposure to nitrogen dioxide $\left(\mathrm{NO}_{2}\right)$ and particulate matter with a diameter of less than $10 \mu \mathrm{m}\left(\mathrm{PM}_{10}\right)$ and repeated measures of $\mathrm{S}_{\text {raw }}$ at ages $3,5,8$, and 11 years in a birth cohort from Manchester [14]. A quantitative comparison of the observed air pollution effects between our study and the other studies is limited by the different outcomes and exposure measures that were used.

An advantage of the current analysis over the earlier analyses at age 4 is that we were able to investigate the relevance of early life versus recent exposure. The more consistent associations with exposure at the current address as compared to exposure at the birth address are consistent with findings for $\mathrm{FEV}_{1}$ and $\mathrm{FVC}$ at age 6-8 years from five European birth cohorts including PIAMA [26]. Further evidence for an association of airway resistance with current air pollution exposure comes from the German study [13]. So far, only the Swedish study has assessed associations of airway resistance with air pollution exposure at different time points and found, opposite to the present study, associations with exposure during the first year, but not during the year preceding the lung function measurements [11].

Oxidative stress-induced inflammation has been hypothesized as a main mechanism underlying the respiratory health effects of air pollution [6]. We observed associations with airway resistance in particular for the more traffic-related pollutants $\mathrm{NO}_{2}, \mathrm{NO}_{\mathrm{x}}$ and $\mathrm{PM}_{2.5}$ absorbance and less consistently with particulate matter mass concentrations $\left(\mathrm{PM}_{2.5}, \mathrm{PM}_{10}\right.$, and $\left.\mathrm{PM}_{\text {coarse }}\right)$. However, the relevance of specific air pollutants remains unclear due to the high spatial correlation between pollutants, which is an inherent limitation of population studies investigating air pollution effects under real life conditions. Also, the more consistent associations with $\mathrm{NO}_{2}, \mathrm{NO}_{\mathrm{x}}$ and $\mathrm{PM}_{2.5}$ absorbance could be at least partly explained by the better performance of the land-use regression models for $\mathrm{NO}_{2}, \mathrm{NO}_{\mathrm{x}}$ and $\mathrm{PM}_{2.5}$ absorbance as compared to the PM models (see Additional file 1: Table S1) and consequently a smaller exposure measurement error for these pollutants. Since $R_{\text {int }}$ measurements are probably influenced by the resistance of small airways, we speculate that an effect of nitrogen oxides and small particles may be due to penetration into small airways.

It can be argued that a potential limitation of our study is that the land-use regression models that we used to estimate exposures were based on measurements performed in 2008-2010, while study participants were born in 1996/97 and airway resistance measurements at age 8 were performed in 2004/2005. However, several studies from Europe and North America have demonstrated that spatial contrasts of air pollutants, in particular $\mathrm{NO}_{2}$ and elemental carbon are stable over periods of 7 and more years [27-29]. Moreover, air pollution measurements performed in 2008-2010 were highly correlated with air pollution measurements in 1999-2000 [30]. However, associations of $R_{\text {int }}$ at age 8 with exposure at the birth address were about doubled when we used back-extrapolated exposures and estimated exposures from an older land-use regression model that was based on the 1999-2000 measurements suggesting that using non back-extrapolated ESCAPE exposure estimates most likely results in an underestimation of associations with $R_{\text {int }}$.

Another potential limitation of our study is that we restricted our study to air pollution exposure at the residential address and did not include non-residential exposures (e.g. at school) and time-activity patterns. Although data from our cohort and the Swedish study show high correlations between home and school address exposures during the primary school period [31, 32], we cannot rule out that measurement error is differential, e.g. that it differs between asthmatic and non-asthmatic children, because of asthmatic children possibly being more likely to spend more time at home.

Children with at least one allergic parent were overrepresented in our study sample (75\% vs $51 \%$ in the full PIAMA cohort). Together with the fact that highly educated Dutch parents are over-represented in the PIAMA cohort, this may limit the generalizability of our findings to the full PIAMA cohort and to the general population.

\section{Conclusions}

In conclusion, our results support the hypothesis that air pollution exposure is associated with a higher airway resistance in schoolchildren.

\section{Additional file}

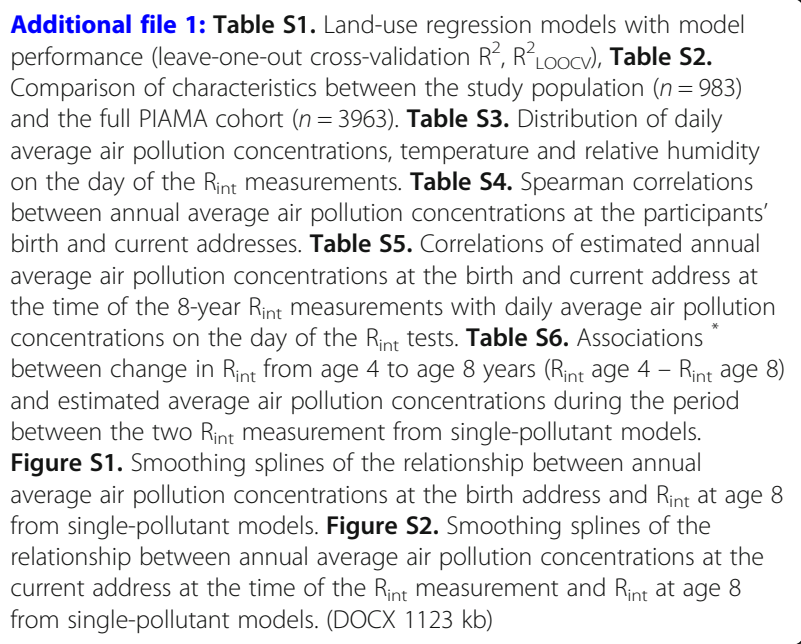

Additional file 1: Table S1. Land-use regression models with model performance (leave-one-out cross-validation $R^{2}, R^{2}$ LoocV), Table S2. Comparison of characteristics between the study population $(n=983)$ and the full PIAMA cohort ( $n=3963)$. Table S3. Distribution of daily average air pollution concentrations, temperature and relative humidity on the day of the $\mathrm{R}_{\text {int }}$ measurements. Table S4. Spearman correlations between annual average air pollution concentrations at the participants' birth and current addresses. Table S5. Correlations of estimated annual average air pollution concentrations at the birth and current address at the time of the 8-year $R_{\text {int }}$ measurements with daily average air pollution concentrations on the day of the $R_{\text {int }}$ tests. Table S6. Associations * between change in $R_{\text {int }}$ from age 4 to age 8 years $\left(R_{\text {int }}\right.$ age $4-R_{\text {int }}$ age 8 ) and estimated average air pollution concentrations during the period between the two $R_{\text {int }}$ measurement from single-pollutant models. Figure S1. Smoothing splines of the relationship between annual average air pollution concentrations at the birth address and $R_{\text {int }}$ at age 8 from single-pollutant models. Figure S2. Smoothing splines of the relationship between annual average air pollution concentrations at the current address at the time of the $R_{\text {int }}$ measurement and $R_{\text {int }}$ at age 8 from single-pollutant models. (DOCX $1123 \mathrm{~kb}$ ) 


\section{Abbreviations}

ESCAPE: European Study of Cohorts for Air Pollution Effects; FEV ${ }_{1}$ : Forced expiratory volume within $1 \mathrm{~s} ; \mathrm{NO}_{2}$ : Nitrogen dioxide; $\mathrm{NO}_{x}$ : Nitrogen oxides; PIAMA: Prevention and Incidence of Asthma and Mite Allergy; $\mathrm{PM}_{10}$ : Particulate matter with a diameter of less than $10 \mu \mathrm{m} ; \mathrm{PM}_{2.5}$ : Particulate matter with a diameter of less than $2.5 \mu \mathrm{m} ; \mathrm{PM}_{\text {coarse: }}$ Particulate matter with a diameter 2.5-10 um; Raw: Airway resistance; $R_{\text {int: }}$ Interrupter resistance; TRAPCA: Traffic-Related Air Pollution and Childhood Asthma

\section{Acknowledgements}

The authors thank all the children and their parents for their participation. The authors also thank all the field workers and laboratory personnel involved for their efforts, and Marjan Tewis for data management.

\section{Funding}

The PIAMA study has received funding from the Netherlands Organization for Health Research and Development, the Netherlands Organization for Scientific Research, the Lung Foundation Netherlands (previously Asthma Fund), the Netherlands Ministry of Spatial Planning, Housing, and the Environment, and the Netherlands Ministry of Health, Welfare, and Sport. Ulrike Gehring was supported by a research fellowship from the Netherlands Organization for Scientific Research (NWO).The sponsors had no role in study design; in the collection, analysis, and interpretation of data; in the writing of the report; and in the decision to submit the report for publication.

\section{Availability of data and materials}

The datasets during and/or analyzed during the current study are available from the corresponding author on reasonable request.

\section{Authors' contributions}

$\mathrm{BB}, \mathrm{HAS}$ and JCdJ conceived the PIAMA study and secured funding. IF and UG designed the present study, had full access to all the data in the study, carried out the statistical analysis, wrote the initial draft and had final responsibility for the decision to submit for publication. BB contributed to the air pollution exposure assessment. All authors (i) provided substantial contributions to the conception or design of the work, or the acquisition, analysis, or interpretation of data for the work, (ii) revised the manuscript for important intellectual content, (iii) approved the final version, and (iv) agreed to be accountable for all aspects of the work.

\section{Ethics approval and consent to participate}

Ethical approval was obtained from authorized institutional review boards. Children's parents or legal guardians and children themselves provided written informed consent.

\section{Consent for publication}

Not applicable.

\section{Competing interests}

Professor Gerard H. Koppelman reports grants from the Lung Foundation Netherlands, TEVA Netherlands, the UBBO EMMIUS Foundation, and the TETRI Foundation outside the submitted work.

\section{Publisher's Note}

Springer Nature remains neutral with regard to jurisdictional claims in published maps and institutional affiliations.

\section{Author details}

1 Institute for Risk Assessment Sciences, Utrecht University, P.O. Box 80178 3508TD Utrecht, The Netherlands. ${ }^{2}$ Department of Pediatrics, Division of Respiratory Medicine, Erasmus University Medical Center/Sophia Children's Hospital, Rotterdam, The Netherlands. ${ }^{3} J u l i u s$ Center for Health Sciences and Primary Care, University Medical Center Utrecht, Utrecht, The Netherlands. ${ }^{4}$ Center for Nutrition, Prevention and Health Services, National Institute of Public Health and the Environment, Bilthoven, The Netherlands. ${ }^{5}$ Department of Pediatric Pulmonology, Beatrix Children's Hospital, University Medical Center Groningen, University of Groningen, Groningen, The Netherlands. ${ }^{6}$ Groningen Research Institute for Asthma and COPD, University of Groningen, Groningen, The Netherlands. 'Department of Epidemiology, University Medical Center Groningen, University of Groningen, Groningen, The Netherlands.
Received: 11 January 2018 Accepted: 11 July 2018

Published online: 17 July 2018

\section{References}

1. Martinez FD. The origins of asthma and chronic obstructive pulmonary disease in early life. Proc Am Thorac Soc. 2009;6:272-7.

2. Sears MR, Greene JM, Willan AR, Wiecek EM, Taylor DR, Flannery EM, Cowan JO, Herbison GP, Silva PA, Poulton R. A longitudinal, population-based, cohort study of childhood asthma followed to adulthood. N Engl J Med. 2003;349:1414-22

3. Postma DS, Bush A, van den Berge M. Risk factors and early origins of chronic obstructive pulmonary disease. Lancet. 2015;385:899-909.

4. Stern DA, Morgan WJ, Wright AL, Guerra S, Martinez FD. Poor airway function in early infancy and lung function by age 22 years: a non-selective longitudinal cohort study. Lancet. 2007;370:758-64.

5. Schultz ES, Litonjua AA, Melen E. Effects of long-term exposure to trafficrelated air pollution on lung function in children. Curr Allergy Asthma Rep. 2017:17:41.

6. Health Effects Institute Panel on the Health Effects of Traffic-Related Air Pollution: Traffic-Related Air Pollution: A Critical Review of the Literature on Emissions, Exposure, and Health Effects. In., vol. Special Report 17. Boston, Massachusetts, USA: Health Effects Institute; 2010.

7. Gotschi T, Heinrich J, Sunyer J, Kunzli N. Long-term effects of ambient air pollution on lung function: a review. Epidemiology. 2008;19:690-701.

8. Merkus PJ, Mijnsbergen JY, Hop WC, de Jongste JC. Interrupter resistance in preschool children: measurement characteristics and reference values. Am J Respir Crit Care Med. 2001;163:1350-5.

9. Arets HG, Brackel HJ, van der Ent CK. Applicability of interrupter resistance measurements using the MicroRint in daily practice. Respir Med. 2003:97:366-74

10. Kaminsky DA. What does airway resistance tell us about lung function? Respir Care. 2012;57:85-96.

11. Schultz ES, Hallberg J, Gustafsson PM, Bottai M, Bellander T, Bergstrom A, Kull I, Gruzieva O, Thunqvist P, Pershagen G, et al. Early life exposure to traffic-related air pollution and lung function in adolescence assessed with impulse oscillometry. J Allergy Clin Immunol. 2016;138:930-2. e935

12. Eenhuizen $E$, Gehring U, Wijga AH, Smit HA, Fischer $P$, Brauer $M$, Koppelman $\mathrm{GH}$, Kerkhof $\mathrm{M}$, de Jongste JC, Brunekreef $\mathrm{B}$, et al. Traffic related air pollution is related to interrupter resistance in four-year old children. Eur Respir J. 2012;41:1257-63.

13. Sugiri D, Ranft U, Schikowski T, Kramer U. The influence of large-scale airborne particle decline and traffic-related exposure on children's lung function. Environ Health Perspect. 2006;114:282-8.

14. Molter A, Agius RM, de Vocht F, Lindley S, Gerrard W, Lowe L, Belgrave D, Custovic A, Simpson A. Long-term exposure to PM10 and NO2 in association with lung volume and airway resistance in the MAAS birth cohort. Environ Health Perspect. 2013;121:1232-8.

15. Brunekreef B, Smit J, de Jongste J, Neijens H, Gerritsen J, Postma D, Aalberse R, Koopman L, Kerkhof M, Wijga A, et al. The prevention and incidence of asthma and mite allergy (PIAMA) birth cohort study: design and first results. Pediatr Allergy Immunol. 2002;13(Suppl 15):55-60.

16. Wijga AH, Kerkhof M, Gehring U, de Jongste JC, Postma DS, Aalberse RC, Wolse AP, Koppelman GH, van Rossem L, Oldenwening M, et al. Cohort profile: the prevention and incidence of asthma and mite allergy (PIAMA) birth cohort. Int J Epidemiol. 2014;43:527-35.

17. Brussee JE, Smit HA, Koopman LP, Wijga AH, Kerkhof M, Corver K, Vos AP, Gerritsen J, Grobbee DE, Brunekreef B, et al. Interrupter resistance and wheezing phenotypes at 4 years of age. Am J Resp Crit Care Med. 2004;169:209-13.

18. Eeftens M, Beelen R, de Hoogh K, Bellander T, Cesaroni G, Cirach M, Declercq C, Dedele A, Dons E, de Nazelle A, et al. Development of land use regression models for PM2.5, PM2.5 absorbance, PM10 and PMcoarse in 20 European study areas; results of the ESCAPE project. Environ Sci Technol. 2012;46:11195-205.

19. Beelen R, Hoek G, Vienneau D, Eeftens M, Dimakopoulou K, Pedeli X, Tsai MY, Kunzli N, Schikowski T, Marcon A, et al. Development of NO2 and NOx land use regression models for estimating air pollution exposure in 36 study areas in Europe - the ESCAPE project. Atmos Environ. 2013;72:10-23.

20. Brauer M, Hoek G, van Vliet P, Meliefste K, Fischer P, Gehring U, Heinrich J, Cyrys J, Bellander $T$, Lewne $M$, et al. Estimating long-term average 
particulate air pollution concentrations: application of traffic indicators and geographic information systems. Epidemiology. 2003;14:228-39.

21. Eeftens M, Tsai MY, Ampe C, Anwander B, Beelen R, Bellander T, Cesaroni G, Cirach M, Cyrys J, de Hoogh K, et al. Spatial variation of PM 2.5 , PM 10 , PM 2.5 absorbance and PM coarse concentrations between and within 20 European study areas and the relationship with NO 2 - results of the ESCAPE project. Atmos Environ. 2012;62:303-17.

22. Pinart M, Benet M, Annesi-Maesano I, von Berg A, Berdel D, Carlsen KC, Carlsen KH, Bindslev-Jensen C, Eller E, Fantini MP, et al. Comorbidity of eczema, rhinitis, and asthma in IgE-sensitised and non-lgE-sensitised children in MeDALL: a population-based cohort study. Lancet Respir Med. 2014;2:131-40

23. Merkus PJ, Stocks J, Beydon N, Lombardi E, Jones M, McKenzie SA, Kivastik J, Arets BG, Stanojevic $S$. Reference ranges for interrupter resistance technique: the Asthma UK initiative. Eur Respir J. 2010;36:157-63.

24. McNulty W, Usmani OS. Techniques of assessing small airways dysfunction. European clinical respiratory journal. 2014;1

25. Beydon N, Mahut B, Maingot L, Guillo H, La Rocca MC, Medjahdi N, Koskas M, Boule M, Delclaux C. Baseline and post-bronchodilator interrupter resistance and spirometry in asthmatic children. Pediatr Pulmonol. 2012;47:987-93.

26. Gehring U, Gruzieva O, Agius RM, Beelen R, Custovic A, Cyrys J, Eeftens M, Flexeder C, Fuertes E, Heinrich J, et al. Air pollution exposure and lung function in children: the ESCAPE project. Environ Health Perspect. 2013;121:1357-64.

27. Eeftens M, Beelen R, Fischer P, Brunekreef B, Meliefste K, Hoek G. Stability of measured and modelled spatial contrasts in $\mathrm{NO}(2)$ over time. Occup Environ Med. 2011;68:765-70.

28. Cesaroni G, Porta D, Badaloni C, Stafoggia M, Eeftens M, Meliefste K, Forastiere F. Nitrogen dioxide levels estimated from land use regression models several years apart and association with mortality in a large cohort study. Environ Health. 2012;11:48.

29. Gulliver J, de HK, Hansell A, Vienneau D. Development and backextrapolation of $\mathrm{NO} 2$ land use regression models for historic exposure assessment in Great Britain. Environ Sci Technol. 2013:47:7804-11.

30. Durant JL, Beelen R, Eeftens M, Meliefste K, Cyrys J, Heinrich J, Bellander T, Lewne M, Brunekreef B, Hoek G. Comparison of ambient airborne PM(2).(5), PM(2).(5) absorbance and nitrogen dioxide ratios measured in 1999 and 2009 in three areas in Europe. Sci Total Environ. 2014;487:290-8.

31. Gruzieva O, Bellander T, Eneroth K, Kull I, Melen E, Nordling E, van HM, Wickman M, Moskalenko V, Hulchiy O, et al. Traffic-related air pollution and development of allergic sensitization in children during the first 8 years of life. J Allergy Clinlmmunol. 2012;129:240-6.

32. Bilenko N, van Rossem L, Brunekreef B, Beelen R, Eeftens M, Hoek G, Houthuijs D, de Jongste JC, van Kempen E, Koppelman GH, et al. Trafficrelated air pollution and noise and children's blood pressure: results from the PIAMA birth cohort study. Eur J Prev Cardiol. 2015;22:4-12.

Ready to submit your research? Choose BMC and benefit from:

- fast, convenient online submission

- thorough peer review by experienced researchers in your field

- rapid publication on acceptance

- support for research data, including large and complex data types

- gold Open Access which fosters wider collaboration and increased citations

- maximum visibility for your research: over $100 \mathrm{M}$ website views per year

At BMC, research is always in progress.

Learn more biomedcentral.com/submissions 